This item was submitted to Loughborough's Research Repository by the author.

Items in Figshare are protected by copyright, with all rights reserved, unless otherwise indicated.

\title{
A review of some tribo-dynamics phenomena from micro to nano-scale conjunctions
}

PLEASE CITE THE PUBLISHED VERSION

PUBLISHER

(C) Elsevier

VERSION

AM (Accepted Manuscript)

LICENCE

CC BY-NC-ND 4.0

\section{REPOSITORY RECORD}

Rahnejat, Homer, P.M. Johns-Rahnejat, M. Teodorescu, Vasilis Votsios, and M. Kushwaha. 2019. "A Review of Some Tribo-dynamics Phenomena from Micro to Nano-scale Conjunctions". figshare.

https://hdl.handle.net/2134/6714. 
This item was submitted to Loughborough's Institutional Repository (https://dspace.lboro.ac.uk/) by the author and is made available under the following Creative Commons Licence conditions.

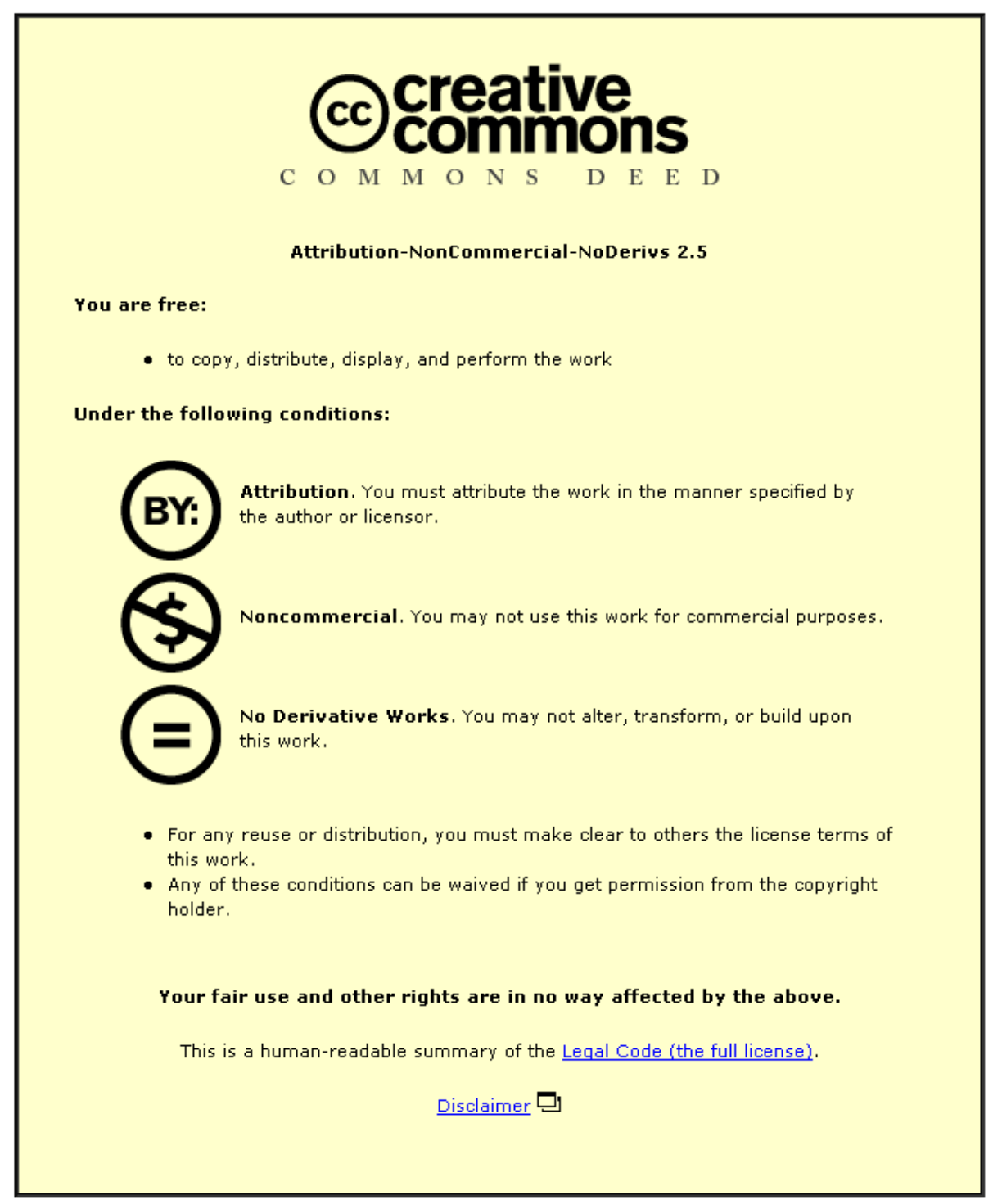

For the full text of this licence, please go to: http://creativecommons.org/licenses/by-nc-nd/2.5/ 


\section{Author's Accepted Manuscript}

A review of some tribo-dynamics phenomena from micro to nano-scale conjunctions

H. Rahnejat, P.M. Johns-Rahnejat, M. Teodorescu, V. Votsios, M. Kushwaha

PII:

S0301-679X(09)00110-8

DOI: doi:10.1016/j.triboint.2009.04.044

Reference: JTRI 1997

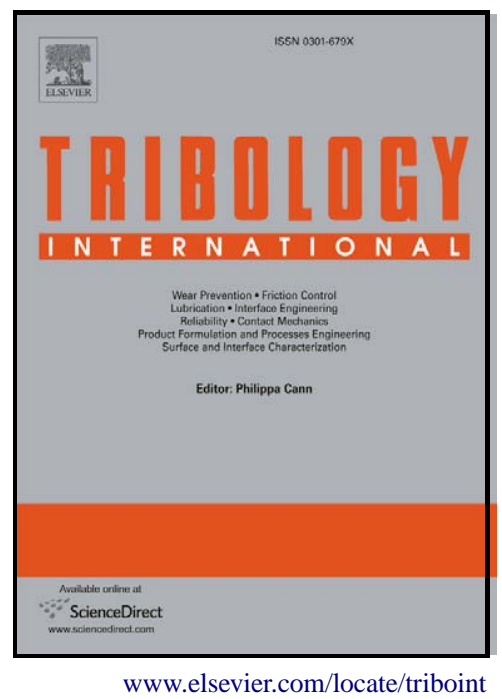

To appear in: $\quad$ Tribology International

Received date: $\quad 29$ July 2008

Revised date: $\quad 14$ April 2009

Accepted date: $\quad 16$ April 2009

Cite this article as: H. Rahnejat, P.M. Johns-Rahnejat, M. Teodorescu, V. Votsios and M. Kushwaha, A review of some tribo-dynamics phenomena from micro to nano-scale conjunctions, Tribology International, doi:10.1016/j.triboint.2009.04.044

This is a PDF file of an unedited manuscript that has been accepted for publication. As a service to our customers we are providing this early version of the manuscript. The manuscript will undergo copyediting, typesetting, and review of the resulting galley proof before it is published in its final citable form. Please note that during the production process errors may be discovered which could affect the content, and all legal disclaimers that apply to the journal pertain. 


\title{
A review of some tribo-dynamics phenomena from micro to nano-scale conjunctions
}

\author{
H. Rahnejat ${ }^{1}$, P.M. Johns-Rahnejat ${ }^{2}$ \\ M. Teodorescu ${ }^{3}$, V. Votsios ${ }^{1}$ and M. Kushwaha ${ }^{4}$ \\ 1 Wolfson School of Mechanical and Manufacturing Engineering \\ Loughborough University, Loughborough, UK \\ 2 Previously at Mechanical Engineering Department, Imperial College, London \\ 3 School of Engineering, Cranfield University, Cranfield, UK \\ 4 Ford Motor Company, Dunton, UK
}

\begin{abstract}
:
The paper provides some highlights in the developments of theories of lubrication and contact mechanics from early pioneering works of Reynolds and Hertz to the establishment of elastohydrodynamic phenomenon by Ertel and Grubin. Some historical discourse is made on the development of elastohydrodynamic theory in the past 5-6 decades, with particular attention paid to the contact of rolling element bearings. The steady miniturisation of devices has led to progressively smaller contacts of individual features with lighter load share and diminishing gaps. The ultra-thin films are supported by interaction potentials that significantly deviate from bulk continuum behaviour of lubricating films, with insignificant contributions due to viscous-elastic nature of contacts. Using the same theme of rolling element contacts, the paper highlights the action of some of these dominant forces at close range.
\end{abstract}

Keywords: elastohydrodynamics, ultra-film films, adhesion, meniscus action, hydration

\section{Nomenclature:}

$\begin{array}{ll}a & : \text { Local Hertzian semi half-width } \\ a_{0} & : \text { Central contact Hertzian semi-half-width } \\ E & : \text { Modulus of elasticity } \\ E^{\prime} & : \text { Reduced elastic modulus } \\ F & : \text { Force } \\ F_{a} & : \text { Adhesive force } \\ F_{h} & : \text { Hydration force } \\ F_{m} & : \text { Meniscus force } \\ G & : \text { Modulus of rigidity } \\ h & : \text { Film thickness } \\ h_{0} \text { or } h_{\text {ref }} & : \text { Rigid gap } \\ K & : \text { Contact stiffness } \\ L & : \text { Roller length } \\ m & : \text { Mass }\end{array}$




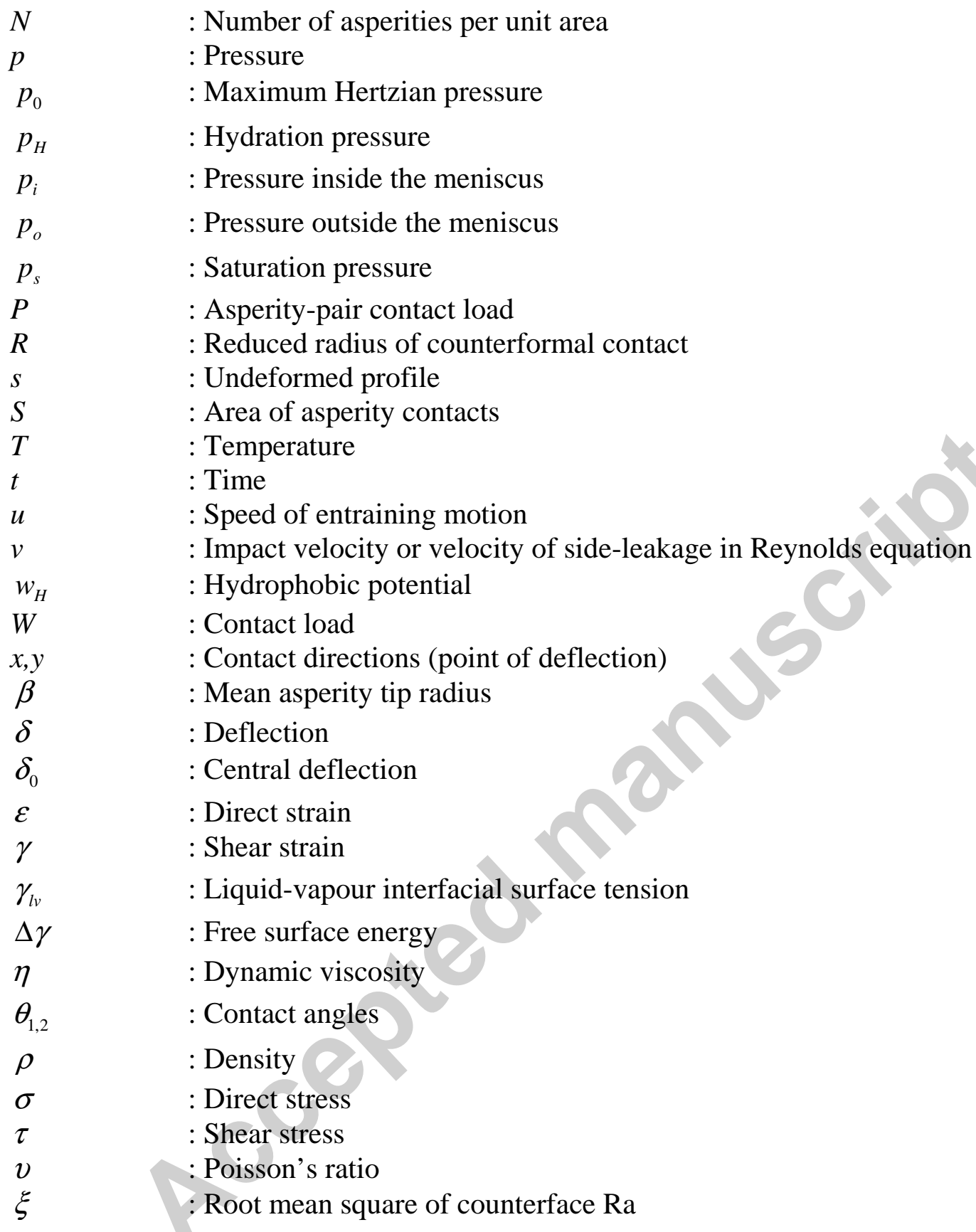

\section{Subscripts:}

$1 \quad:$ Denotes the point of application of pressure

$0 \quad:$ Belongs to the centre of contact or at ambient pressure

a : Adhesive contribution

\section{Superscripts:}

$\begin{array}{ll}. & : \text { First differential with respect to time } \\ . . & : \text { Second differential with respect to time }\end{array}$




\section{1- Introduction}

In 1964 a Government appointed committee was set up to mitigate the untoward effects of friction and wear in the British industry, the report of which was published in 1966 [1]. It was clear to the committee that the promotion of a film of suitable lubricant in load bearing and power transmitting conjunctions would represent the main aim of their work. Therefore, the three highlighted fields of study were identified as friction, wear and lubrication (hence tribology).

By the time of their deliberations, important discoveries had already been made. The viscous behaviour of fluids, based on the Newtonian model had been understood for some time (Navier [2] and Stokes [3]) and the formation of a fluid film between closely adhering bodies in relative motion was predicted through hydrodynamic action (Tower [4] and Reynolds [5]). Most pertinently, Grubin [6] (based on the work of Ertel) had provided a hypothesis for fluid film formation, based on viscous-elastic behaviour of concentrated non-conforming contacts, one that had strangely evaded the attention of scientists, given that Hertzian contact mechanics had already been established in 1881 [7] and hydrodynamics by 1896 [5]. This viscous-elastic behaviour is better known as elastohydrodynamics. The implications of Ertel and Grubin's hypothesis had been understood by early studies carried out by Petrusevitch [8], and Dowson and Higginson $[9,10]$ for line contacts, the latter obtaining the secondary pressure peaks that were sensitive to changes in load, kinematics of contact and bulk lubricant rheology. After Dowson and Higginson's work a flurry of research led to other solutions for elastohydrodynamics of line contacts, for example by Archard et al [11], Stephenson and Osterle [12], and some included the effects of friction and thermal distribution, such as Sternlicht et al [13] and Crook [14].

Thus, by the time the committee sat in 1964, significant understanding of thin elastohydrodynamic films, nearly 2 orders of magnitude lower than the hydrodynamic films predicted by Reynolds existed. Soon thereafter the research would provide two dimensional solutions for circular and elliptical point contacts by Cameron and Gohar [15], Archard and Cowking [16] and Ranger et al [17]. It also transpired that the mechanism of elastohydrodynamic lubrication (EHL) extends to the contact of materials of low elastic modulus (Dowson and Swales [18], Hooke and O'Donoghue [19] and Baglin and Archard [20]). By the early 70s the importance of the transient nature of the mechanism of squeeze film action in EHL was realised, explaining the enhanced load carrying capacity of these very thin films (Christiansen [21]). In time, with improved computational models, solutions for transient elastohydrodynamic phenomena have emerged for an assortment of contact conditions; Dowson et al [22], Ma et al [23], Lubrecht and Venner [24], Jalali-Vahid et al [25,26], Kushwaha and Rahnejat [27,28], Mei and Xie [29] and Balakrishnan and Rahnejat [30]). The squeeze film action has provided explanations for long bearing life under oscillating conditions (Kushwaha and Rahnejat [31]), for impact dynamics behaviour (Dowson and Jones [32], Safa and Gohar 
[33], and Al-Samieh and Rahnejat [34]) and most significantly for rough biotribological contacts of endo-articular joints [35].

Interestingly, evolutionary progress in all sciences appears to conform to a generic pattern; a major breakthrough, followed by the establishment of theories and principles, which precede a flurry of applications. For elastohydrodynamics, the ingenious postulate of Ertel and Grubin was underpinned by the theory and practice in the period 1950-1970 by Dowson and his contemporaries. One may refer to this period as the age of elastohydrodynamics.

By the end of the $20^{\text {th }}$ century it had become clear that elastohydrodynamic phenomenon contributed to, and was mostly dominant in, rough contacts of wet contiguous surfaces of high or low elastic moduli, particularly under moderate to high loads. In fact, it was thought that the region of EHL was bounded by hydrodynamics (the upper bound) and boundary interactions (the lower bound). In this region and beyond to hydrodynamic films, the viscous force remains dominant in a world that can be considered as that of Hertz and Reynolds. This was Nature's own choice (such as in endo-articular mammalian joints and the motion of gastropods [36,37]). However, an experiment carried out by Chan and Horn [38] yielded the surprising result of fluid film drainage from vanishing narrow smooth conjunctions in contravention of the continuity of flow condition, an underpinning assumption of Reynolds hydrodynamics. Studies by Matsuoka and Kato [39], Al-Samieh and Rahnejat [40,41] and Al-Samieh, Rahnejat and Dowson [42] also revealed localised contact deformation by a monotonic-oscillatory solvation force due to the constraining effect of very proximate barriers and the molecular rheological behaviour of fluids near them, rather than by any EHL pressures. It transpired that with light loads and very smooth surfaces, intermolecular behaviour and surface energy effects promote fluid film discretisation. The implications of these findings were that the long held Newtonian slow viscous flow model could not be upheld in conjunctions of thickness of several molecular diameter of the intervening fluid. This means that forces other than viscous action of fluid play the dominant role, and thus regimes other than elastohydrodynamics prevail and films of a few nanometres would be expected. A new age in tribology had dawned: nano-tribology. Understanding the balance of forces in such vanishing conjunctions is quite important for the growing field of microelectromechanical systems (MEMS).

This paper presents results for a series of rollers contacting/impacting a flat plate with decreasing roller size and diminishing gap, resulting in films of the order of micrometers down to a few nanometres. Dominance of fluid viscous force and inertial dynamics steadily gives way to other forces, such as intermolecular interactions, meniscus action and solvation/hydration, depending on topography, free surface energy and fluid physical chemistry. It can then be seen that like EHL, nano-tribological phenomena have also been one of Nature's key choices, particularly for some species (e.g. insects and geckos). 


\section{2- Elastostatic contact mechanics}

For a roller loaded against a flat plane the region adjacent to the line of contact deforms as the contact area expands. The new conjunction becomes approximately a very long narrow rectangle for a given applied load. In fact, due to the abrupt geometrical discontinuities at the roller extremities, in practice the footprint shape is a long dumbbell shape, sometimes referred to as a dog-bone (see figure 1, Johns and Gohar [43] and Mostofi and Gohar [44]). Not withstanding this important edge stress discontinuity, it is usual to assume an almost uniform contact pressure distribution along the length of the roller, a condition referred to as an ideal infinite line contact. The analysis is, therefore, confined to the evaluation of the transverse pressure distribution under plane strain condition. Hertz [7] considered this pressure distribution to be half an ellipse for small localised strains when a roller contacts a semi-infinite elastic half-space. For rolling element bearings, however, any abrupt (sharp) edge profiles lead to generation of pressure spikes, which means that the finite length of the contact should be taken into account. As the first step, an elastostatic condition may be assumed, yielding a dry contact.

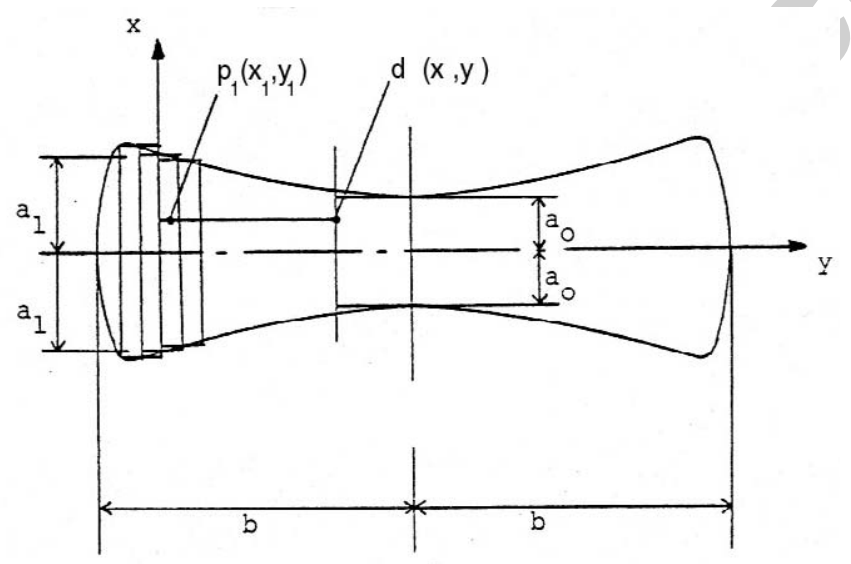

Figure 1: Footprint shape of a roller indenting a semi-infinite elastic half-space

The contact area in figure 1 is sub-divided into a number of rectangular elements, upon each of which a three dimensional pressure distribution is assumed; parabolic in transverse direction and isosceles in the longitudinal direction (see figure 2). Deflection at any point in each rectangular element due to this pressure distribution is obtained as [43]:

$$
\delta(x, y)=\frac{\left(1-v^{2}\right)}{\pi E} \int_{-a_{1}}^{a_{1}} \int_{-c}^{c} \frac{p\left(x_{1}, y_{1}\right)}{\sqrt{\left(x-x_{1}\right)^{2}+\left(y-y_{1}\right)^{2}}} d x_{1} d y_{1}
$$

where:

$$
p\left(x_{1}, y_{1}\right)=\left(1-\frac{\left|y_{1}\right|}{c}\right)\left\{1-\left[\frac{x_{1}}{a_{1}}\right]^{2}\right\}^{1 / 2}
$$




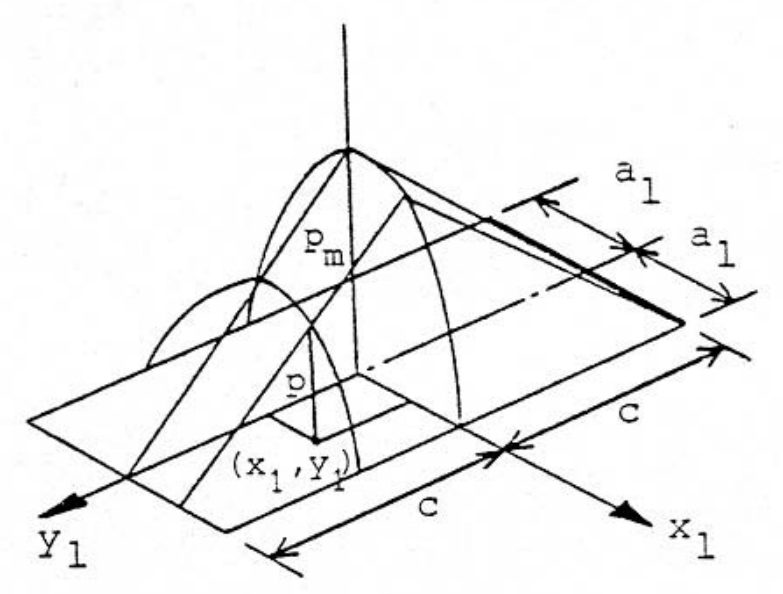

Figure 2: The computing element used in [43]

An analytical solution for a lateral elliptical pressure distribution can now be obtained, if a uniform pressure distribution is also assumed over the length of the roller (i.e. $2 b$ ), the distribution being: $\quad p(x)=p_{0}\left\{1-\frac{x^{2}}{a_{0}^{2}}\right\}^{1 / 2}$. Replacing this into equation (1), with the limits of integration over the length of the contact, the penetration at the centre of the roller can be obtained (see Koshy and Gohar [45]) as:

$\delta_{0}=\frac{a_{0} p_{0}}{\pi E^{\prime}}\left\{\ln \frac{2 L}{a_{0}}+\frac{1}{2}\right\}$

where:

$a_{0}=\left\{\frac{8 W R}{\pi E^{\prime} L}\right\}^{1 / 2}$

and:

$p_{0}=\frac{2 W}{\pi a_{0} L}$

where: $L=2 b$ (see figure 1$)$.

Using the above equations, the footprint shape, deflection and pressure distributions can be obtained for the entire contact based on the computation elements described above (see figure 3). Analyses of this type, in the 70s showed that to reduce the edge effects (often responsible for sub-surface inelastic deformation, causing fatigue spalls) relief radii such as crowns or dub-offs had to be used. In fact, figure 3 shows the pressure distribution and the corresponding footprint shape for a straight-edged roller, with the resulting edge stress discontinuities. 


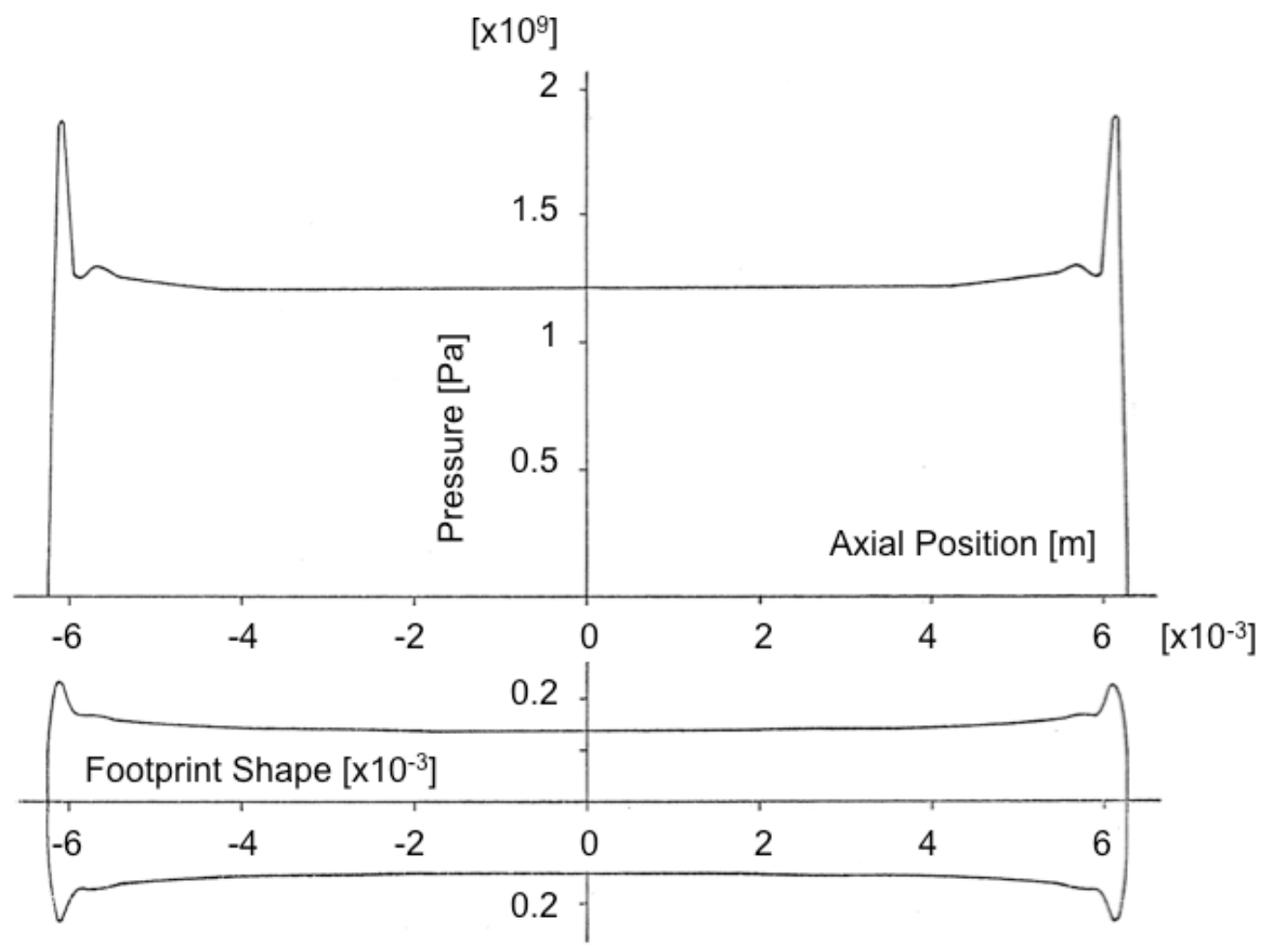

Figure 3: Central axial pressure distribution and footprint shape for load $=3684 \mathrm{~N}$

\section{(after Johns [46])}

Such elastostatic analyses can now be carried out as a matter of course, using finite element analysis (FEA), as long as care is taken in meshing the contact domain, implementing an interval extending beyond the edges of the contact and choosing elements with appropriate constitutive relations. For the finite element problem, the total stress in any nodal location within the computational mesh is defined from the total elastic strain as:

$$
\{\sigma\}=[D]\{\varepsilon\}
$$

where $\{\sigma\}$ is the Cauchy stress in finite-strain problems, $[D]$ is the fourth-order elasticity tensor and $\{\varepsilon\}$ is the total elastic strain or the $\log$ strain in finite-strain problems. For linear elastic materials, the Drucker stability condition must be satisfied. This requires the tensor $[D]$ to be positive definite. For an incompressible material, the Drucker stability condition requires that the change in the stress vector $\{d \sigma\}$, following from any infinitesimal change in strain, $\{d \varepsilon\}$, satisfies the inequality:

$$
\{d \sigma\}\{d \varepsilon\}>0
$$


Thus:

$[D]\{d \varepsilon\}\{d \varepsilon\}>0$

The stress-strain relation is:

$\left\{\begin{array}{l}d \sigma_{1} \\ d \sigma_{2}\end{array}\right\}=\left[\begin{array}{ll}D_{11} & D_{12} \\ D_{21} & D_{22}\end{array}\right]\left\{\begin{array}{l}d \varepsilon_{1} \\ d \varepsilon_{2}\end{array}\right\}$

For material stability, it is clear that $[D]$ must be positive definite, or:

$D_{11}+D_{22}>0, D_{11} D_{22}-D_{12} D_{21}>0$

If the elastic strain can become large, it is necessary to use a hyperelastic model. This, however, is not usual in contact mechanics problems. Then a linear elastic finite element approach suffices. Furthermore, the materials investigated are assumed to have isotropic elastic properties. Therefore, the stress-strain relations are given by the following:

$\left\{\begin{array}{l}\varepsilon_{x x} \\ \varepsilon_{y y} \\ \varepsilon_{z z} \\ \gamma_{x y} \\ \gamma_{y z} \\ \gamma_{z x}\end{array}\right\}=\left[\begin{array}{cccccc}1 / E & -v / E & -v / E & 0 & 0 & 0 \\ -v / E & 1 / E & -v / E & 0 & 0 & 0 \\ -v / E & -v / E & 1 / E & 0 & 0 & 0 \\ 0 & 0 & 0 & 1 / G & 0 & 0 \\ 0 & 0 & 0 & 0 & 1 / G & 0 \\ 0 & 0 & 0 & 0 & 0 & 1 / G\end{array}\right]\left\{\begin{array}{l}\sigma_{x x} \\ \sigma_{y y} \\ \sigma_{z z} \\ \tau_{x y} \\ \tau_{y z} \\ \tau_{z x}\end{array}\right\}$

where the modulus of rigidity, $G=\frac{E}{2(1+v)}$, and note that the matrix above is $[D]^{-1}$.

Figure 4 shows the FEA results for the same conditions as figure 3. It predicts slightly longer footprint (i.e. $1.4 \%$ ), with a narrower width $(1.7 \%$ ) than that in figure 3 . Due to the higher mesh density, a higher pressure spike is expected. The pressure spike is predicted to be around 1.9 GPa by Johns [46], as opposed to the FEA prediction of 2.3 $\mathrm{GPa}$. Elsewhere, the pressures are slightly lower in the current analysis under the same load. 


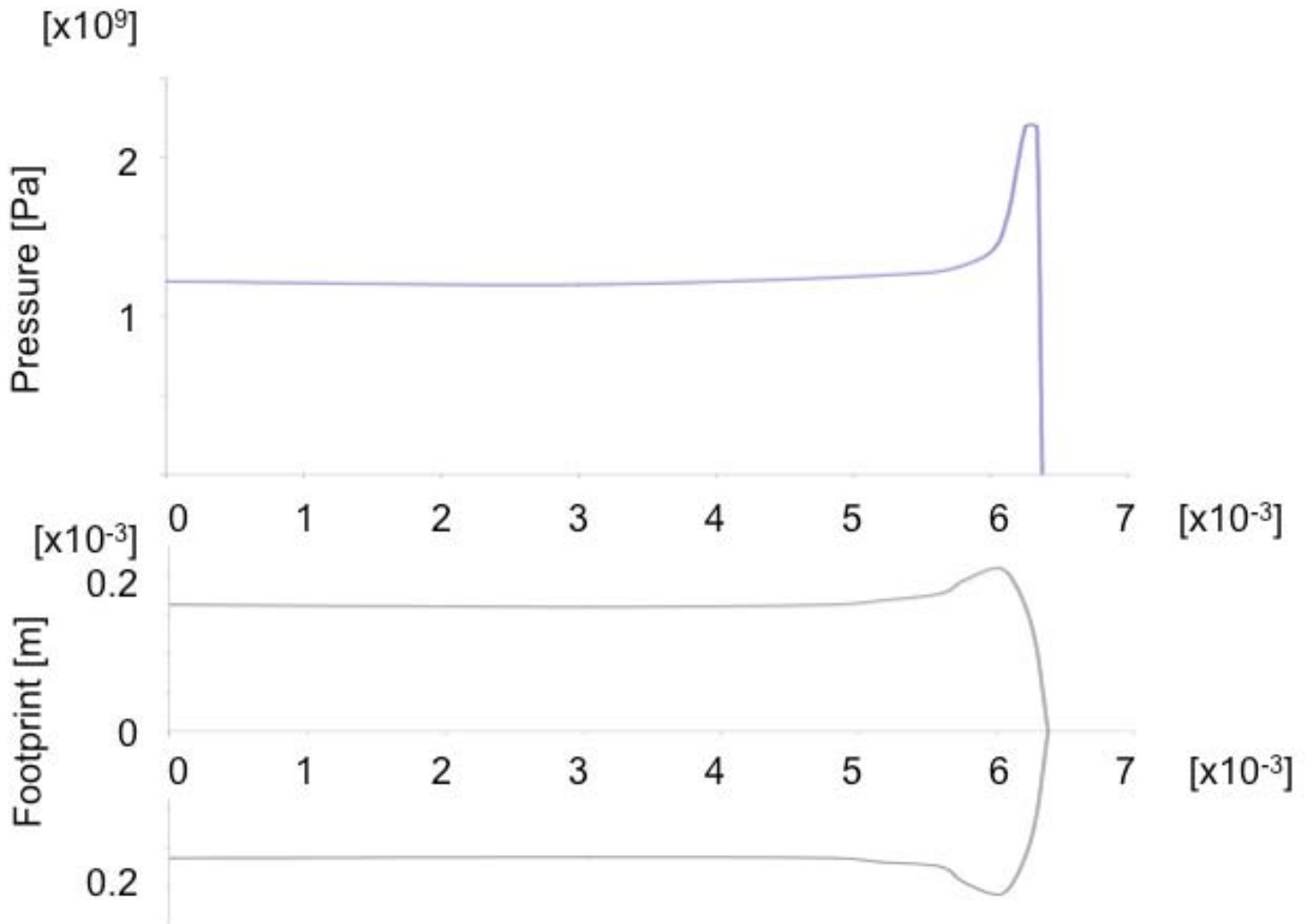

Figure 4: Central axial pressure distribution and footprint shape for load $=3684 \mathrm{~N}$ (after Votsios [47])

Two advantages emerge through the use of FEA, hence the reason for its introduction here. Firstly, some highly loaded contacts are coated with hard wear resistant layers, such as the tappets in automobile valve train systems. Analytical solutions for bonded layered elastic solids assume a rigid substrate and are usually applicable to thin layer thickness (Johnson [48], Naghieh et al [49]). Such assumptions are unnecessary for finite element models. Secondly, the model can be used for impact applications, which are prevalent in the presence of backlash. The classical Hertzian impact does not take into account the increased penetration at the contact extremities.

\section{3- Contact mechanics of layered bonded solids}

Load bearing surfaces are often coated with hard wear resistant layers (e.g. cam-tappet contact [50], ceramic coated bearings for precision spindles) or soft lubricating layers (bearings for space applications). The deviant contact mechanics behaviour of these layered bonded solids from the classical Hertzian theory is not always appreciated in practice, although much research has been devoted to this topic in academe since Sneddon [51]. To illustrate this deviant behaviour, the contact of a typical cobaltchromium roller bearing of radius $6 \mathrm{~mm}$ and length $12 \mathrm{~mm}(E=210 \mathrm{GPa})$, coated with a $40 \mu \mathrm{m}$ layer of alumina $(E=400 \mathrm{GPa})$ is considered, subject to a load of $500 \mathrm{~N}$, indenting a semi-infinite elastic half-space of steel. Figure 5 shows increased 
concentration of stresses at the edges of this unprofiled roller, when the effect of coating is taken into account. Hard coatings protect the substrate as they accommodate the high sub-surface stresses and cope better than the substrate material due to their higher yield stresses. The results show that the use of a hard wear resistant coating, whilst reducing the pressure along most of the roller length, has the adverse effect of concentrating higher stresses at its ends. These induce localised sub-surface shear stresses which should remain within condition specified by the Tresca criterion for hard and brittle ceramic materials to avoid onset of fatigue spalling. An optimum coating thickness is required to ensure this, as well as keeping the maximum shear stresses within the hard layer, away from its interface with the substrate material [52]. This latter point is not often appreciated in practice, where ad hoc applications of coatings often lead to their exfoliation.

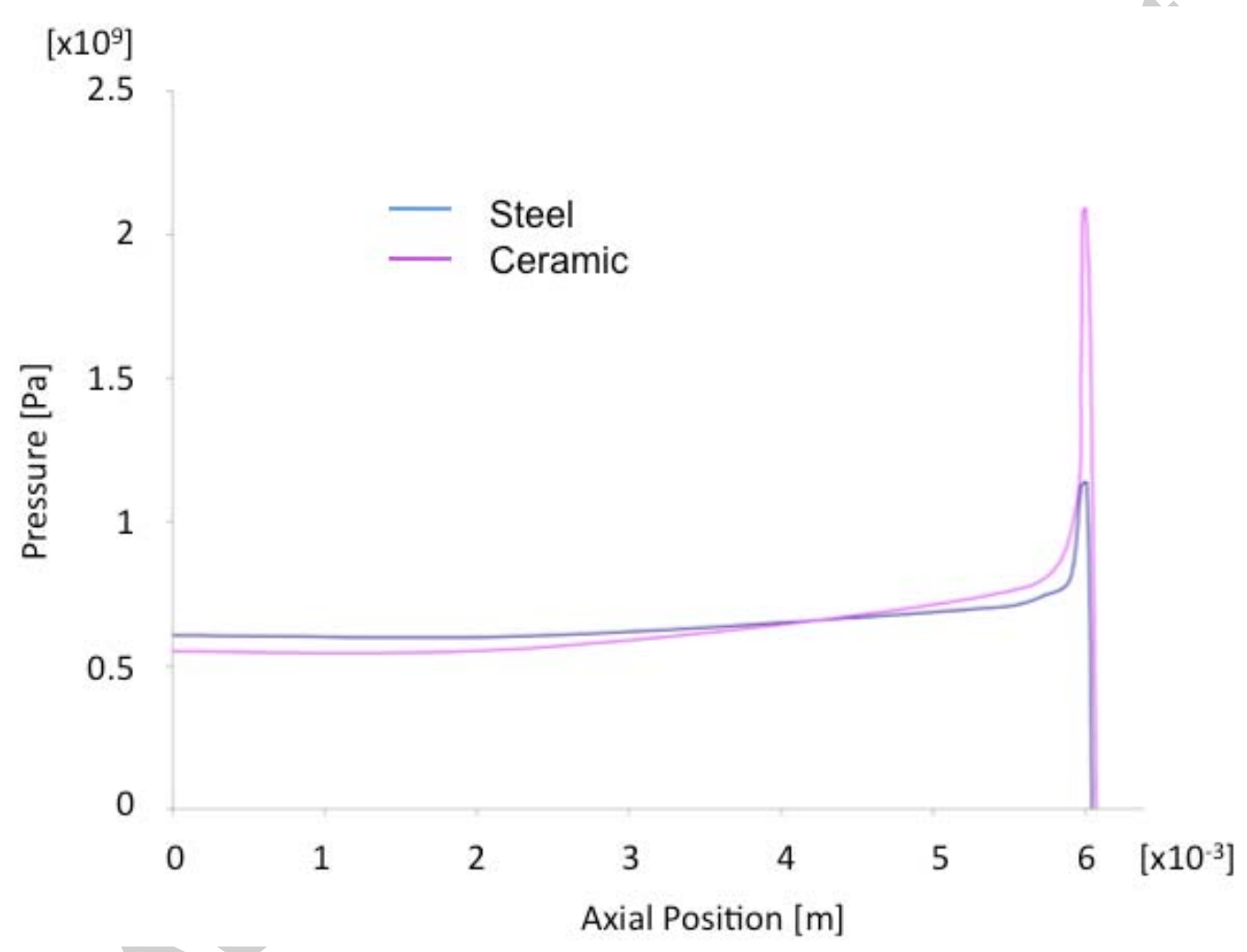

Figure 5: Axi-symmetric axial pressure distributions for a roller indenting a semi-infinite elastic solid $(\operatorname{Load}=500 \mathrm{~N})$

\section{4- Impact dynamics of a roller on an elastic half-space}

The localised Hertzian impact of an assumed roller of mass $m$ impacting a half-space may be described as:

$m \ddot{\delta}=-F$

where $\delta$ is the elastic deflection. If the half-space is assumed to be rigid, the deformation of the roller is localised and remote (its centre remains at the same position). Thus, the 
overall shape of the roller is unaltered (i.e. no modal behaviour due to global deformation is allowed).

For the case of finite line contact of a roller against an elastic half-space, Johns and Gohar [12] have shown that:

$$
F=\frac{\pi L E^{\prime}}{2\left\{\ln \frac{2 L}{a}+\frac{1}{2}\right\}} \delta \approx K \delta
$$

where: $a=\left\{\frac{8 F R}{\pi E^{\prime} L}\right\}^{1 / 2}$ and $p=\frac{2 F}{\pi a L}$, requiring a solution of these three equations in an iterative manner to obtain the impact force.

Substituting for the impact force in equation (12) and multiplying both sides of the equation by $\dot{\delta}$ yields:

$$
\frac{1}{2} \frac{d \dot{\delta}^{2}}{d t}=-\frac{K}{m} \delta \frac{d \delta}{d t}
$$

Integrating both sides of the above equation:

$\frac{1}{2}\left(\dot{\delta}^{2}-v^{2}\right)=-\frac{K}{2 m} \delta^{2}$

Now the maximum penetration is obtained, when: $\dot{\delta}=0$, which yields:

$$
\delta_{\max }=\left(\frac{m v^{2}}{K}\right)^{1 / 2}=\left(\frac{2\left\{\ln \frac{2 L}{a}+\frac{1}{2}\right\} m v^{2}}{\pi L E^{\prime}}\right)^{1 / 2}
$$

Equation (15) can be re-written as:

$$
\left(\frac{d \delta}{d t}\right)^{2}=v^{2}-\frac{K}{m} \delta^{2}
$$

Thus:

$$
d t=\left(v^{2}-\frac{K}{m} \delta^{2}\right)^{-1 / 2} d \delta
$$

Letting $x=\frac{\delta}{\delta_{\max }}$ and integrating the above equation, yields the impact time as: 
$t_{\max }=\frac{2 \delta_{\max }}{v} \int_{0}^{1} \frac{1}{\sqrt{1-x^{2}}} d x=\frac{\pi \delta_{\max }}{v}$

The penetration in a Hertzian impact occurs in a symmetrical manner about the duration $\frac{1}{2} t_{\max }$. Thus, the instantaneous penetration can also be found, using forward differences as:

$\delta_{i}=\delta_{i-1}+\left[\operatorname{sign}\left(t_{\max }-2 \tau_{1}\right)\right] \dot{\delta}_{i-1} \Delta t \quad 0 \leq \tau_{1} \leq t_{\max }$

where: $\dot{\delta}_{i-1}$ is given by equation (17).

The above method is used to study the impact of a steel roller of radius $6 \mathrm{~mm}$ and $12 \mathrm{~mm}$ length, impacting a semi-infinite flat steel plate from a height of $5 \mathrm{~mm}$ under influence of gravity. The height is so chosen in this example to represent the load-change reaction in impacting meshing transmission teeth in sudden throttle tip-in action of light trucks. This condition causes undesired noise propagation from rear wheel drive driveline systems. An initial guess is made for $F$ and values of $a_{0}, p_{0}$ and $\delta_{\text {max }}=\delta_{0}$ are then calculated from the analytic expressions. Finally, the value of load is recalculated from equation (13) and updated. The iterative procedure continues until convergence is obtained for the impact force. The results obtained for the above stated conditions after 3 iterations are:

$F=844 \mathrm{~N}, p=656 \mathrm{MPa}, a=0.068 \mathrm{~mm}, \delta_{\max }=1.23 \mu \mathrm{m}$ and $t_{\max }=12 \mu \mathrm{s}$.

It is noteworthy that the analytical method is based on the determination of maximum deflection at the centre of the contact, which is less than the depth of penetration at the roller edges, where the actual maximum pressures occur.

The corresponding finite element solution provides more instructive information, including an estimate of the edge pressure spikes and the localised shear stresses beneath them (see figures 6 and 7).
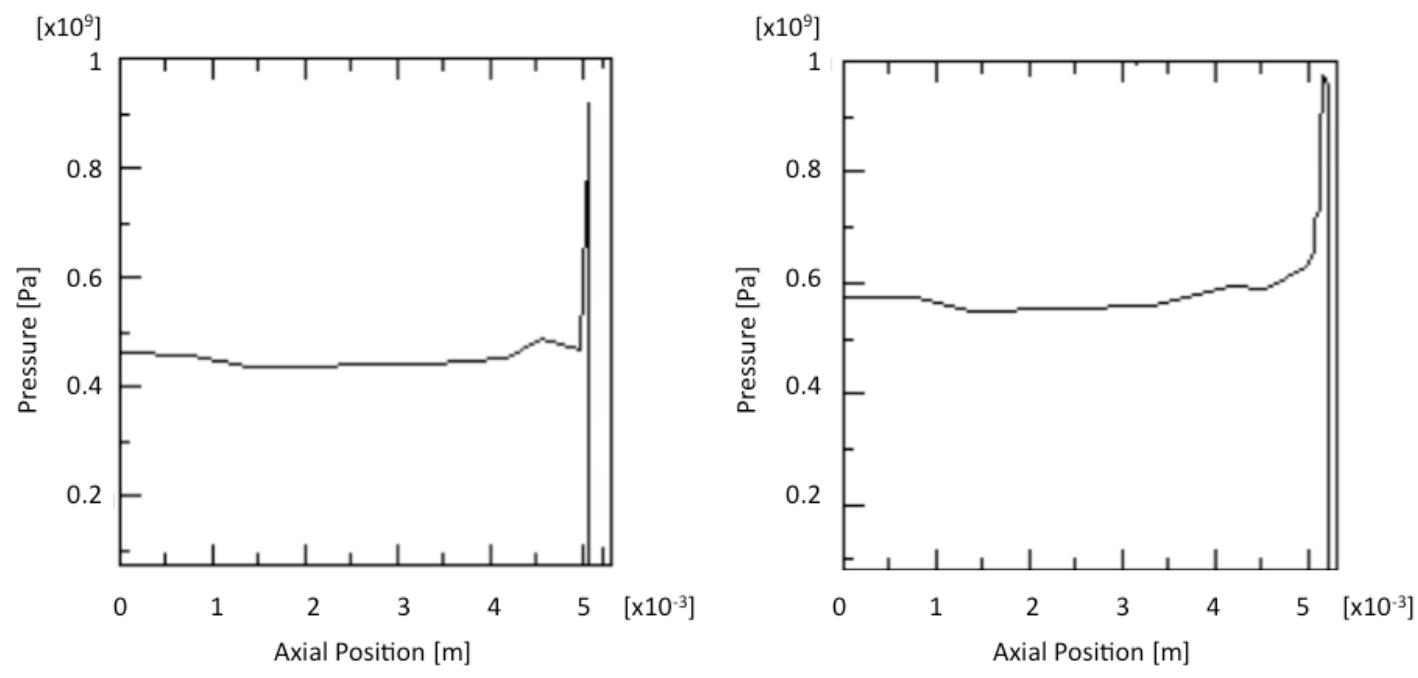


$$
\frac{1}{4} t_{\max } \quad \frac{1}{2} t_{\max }
$$

\section{Figure 6: Transient axial pressure distribution in impact of a roller on an elastic half-space}

The magnitude of pressure spike reaches nearly $1 \mathrm{GPa}$, whereas the maximum value of pressure at the centre of the contact reaches only $600 \mathrm{MPa}, 8.6 \%$ below its predicted value by the analytical calculations. There is more dramatic change in pressure values in the central region of the contact than its edges.

The shear stress variation under the pressure spike is shown in figure 7 .

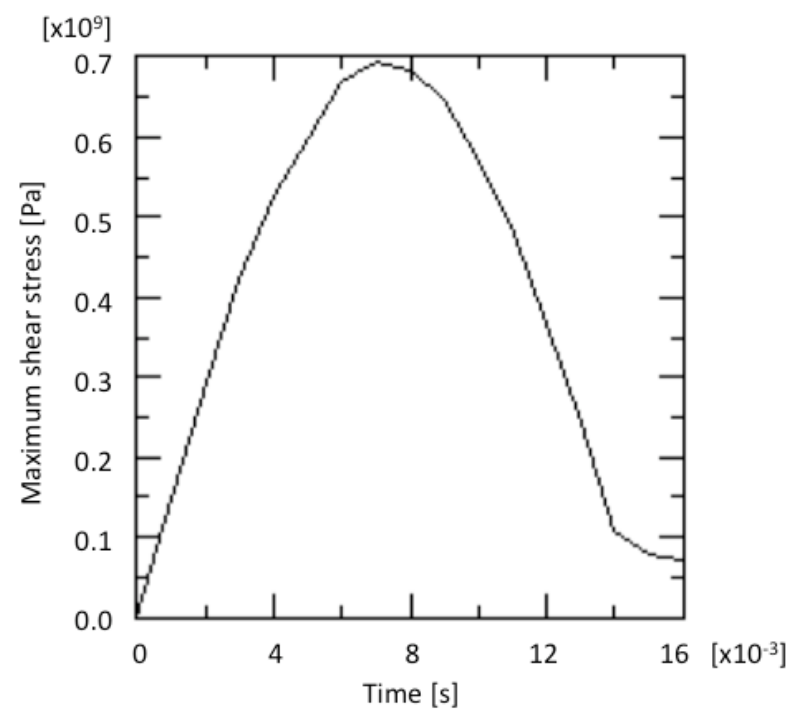

Figure 7: Shear stress variation beneath the pressure spike (roller impact on an elastic half-space)

The shear stress reaches its absolute maximum value of $700 \mathrm{MPa}$, which is still within the elastic limit of the material according to the Tresca criterion. The impact time is predicted to be $14 \mu \mathrm{s}$ (16\% greater than the Hertzian prediction). There is a trailing edge in figure 7 caused by the crudeness of the time interval.

\section{5- Elastohydrodynamics}

Having predicted a diminished thickness of lubricant film, using his hydrodynamic theory, for sufficiently high loads, Reynolds was puzzled to note absence of any wear scars. Nearly half a century later, Ertel and Grubin proposed an explanation for this in the form of combined viscous action of the lubricant (Reynolds' hydrodynamics) and localised elastic deformation of the contiguous surfaces in contact (Hertzian theory). Figure 8 shows a schematic representation of an EHL conjunction. As the lubricant enters into the contact area its viscosity increases dramatically due to high generated 
pressures which deform the contiguous surfaces (localised flattening). Because of the usual small contact area, this localised flattening of the solids promotes a pressure rise, which follows the Hertzian ellipsoidal distribution (for the case of point contacts), giving rise to a nearly flat film as postulated by Grubin [6]. Due to the demands of continuity of flow condition, lubricant progresses towards the exit, where the pressure is at ambient, thus the lubricant viscosity is compelled to decrease. The thinning of the film (shown by $h_{\min }$ in the figure) reduces its localised load carrying capacity, giving rise to the generation of a pressure spike or "pip", which rapidly falls-off to ambient conditions (not included in Grubin's work, but determined by subsequent numerical analyses). The presence of pressure spike was predicted by Petrusevitch [8] and Dowson and Higginson $[9,10]$ from the outset of numerical predictions and has consistently featured ever since in all the subsequent analyses. This hypothesis provided an answer for the absence of wear noted by Reynolds, and as noted in section 1 has led to a fundamental theory which throughout the years has explained the behaviour of, not only man-made machines, but many of natural load bearing conjunctions.

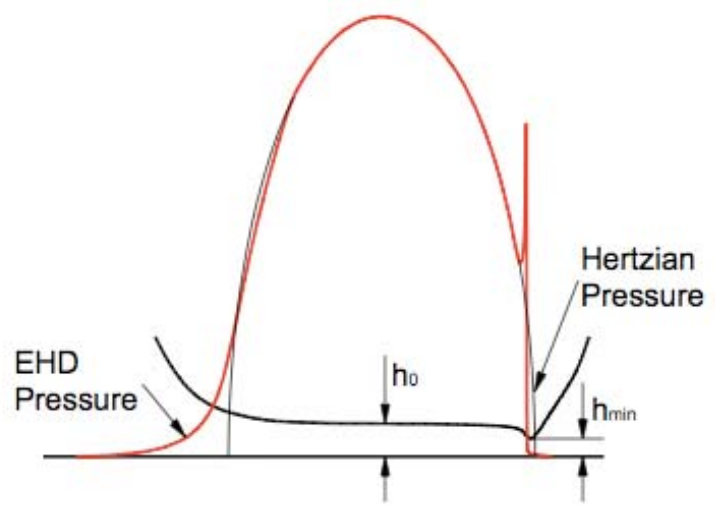

Figure 8: Elastohydrodynamic conjunction

Optical interferometry (see Tolanski [53]) has been used to observe the contours of lubricant film. For point contacts (for example a ball against an optically flat surface) they show, in accord with the Ertel and Grubin postulate, a flat central oil film shape, with a horse-shoe constriction (region of minimum film thickness, $h_{\min }$ ) at the outlet region of the Hertzian contact footprint (see figure 9).

\section{Entraining} motion
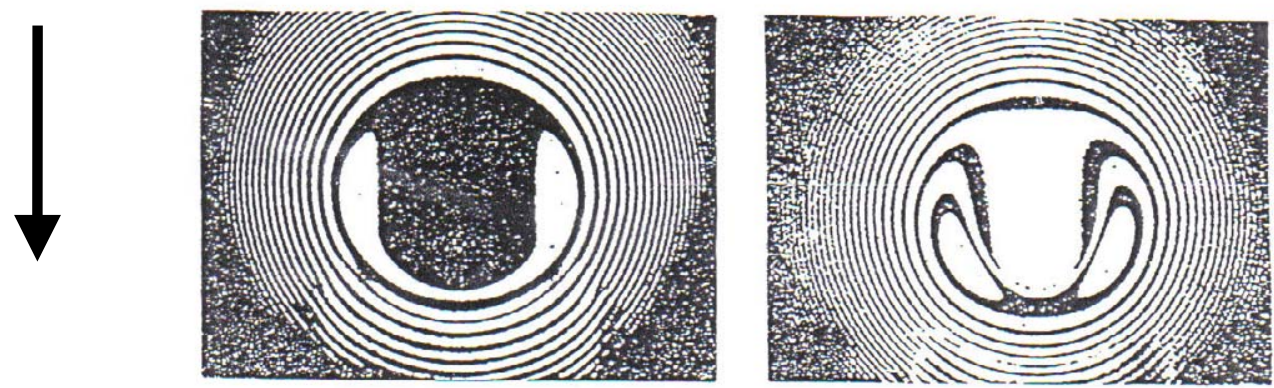


\section{(i)- Starved contact (ii)- Flooded contact}

Figure 9: Interferograms of oil film contours (after Gohar [54] and Jalali-Vahid et al [25])

The shape of EHL pressure distribution is also obtained, using pressure sensitive miniature transducers (such as those reported by Johns-Rahnejat and Gohar [55] and Safa and Gohar [33], to resolve the pressure spike. Johns-Rahnejat [56] obtained crosssectional pressure distributions, using a Manganin pressure transducer deposited on an optically flat glass race of a 3-ball interferometer on the track of a passing steel ball under load. By altering the track of the ball, she obtained a series of such transient crosssectional pressure traces, within the Hertzian region and beyond on the shoulders of the contact. Noting that the inlet meniscus to the contact forms a section of a conic, in line with Prandtl-Hopkins zero reverse boundary condition, she used Tipei's [57] mathematical formulation of the same to determine the inlet meniscus shape and the corresponding wake-flow lines at the outlet beyond the Hertzian circle (see figure 10), where fingers of air cavitate in the lubricant. Carefully laying the obtained pressure traces in the direction of entraining motion between these boundaries resulted in the first ever recording of a measured three-dimensional EHL transient pressure distribution in the form of an isobar (see figure 10). The region of pressure spike in the vicinity of the contact exit boundary, at the rear of the Hertzian region corresponds to the horse-shoe constriction. The overall shape of the isobar is reminiscent of the keyhole shape of the contact, observed in some interferograms, for example by Wedeven [58].

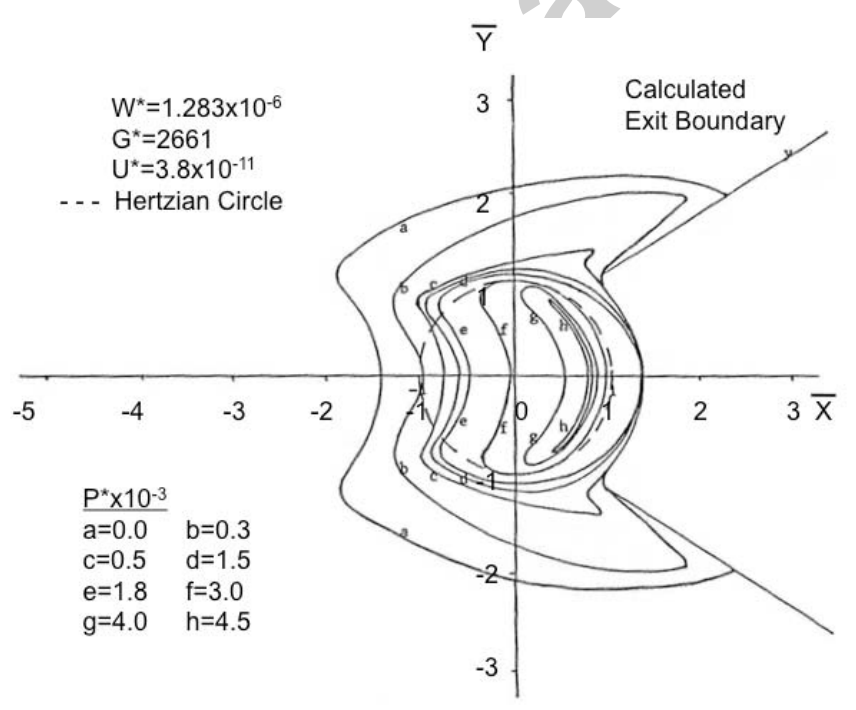

Figure 10: Measured pressure isobars laid according to Prandtl-Hopkins condition $[55,56]$

Returning to the main theme of contact of a roller against a semi-infinite elastic halfspace, it is quite clear that EHL pressure spikes also form at the contact extremities (side constrictions), aside from those at the outlet of the contact. In early $70 \mathrm{~s}$ it was thought that presence of a lubricant film would reduce the magnitude of these pressures. It transpired that on the contrary the pressure spikes increased in magnitude, whilst 
pressures elsewhere along the roller length reduced correspondingly in lubricated cases. Various suppositions have been made as to the underlying reason for these findings, such as inward "diffusion" of lubricant into the contact (Mostofi and Gohar [44]) or on the other hand due to inhibition of lubricant film formation (Wymer and Cameron [59], and Kushwaha, Rahnejat and Gohar [28]).

Solution for the EHL of finite line contact is obtained, using Reynolds equation, elastic film shape and bulk lubricant rheological state equations:

$$
\begin{aligned}
& \frac{\partial}{\partial x}\left(\frac{\rho h^{3}}{\eta} \frac{\partial p}{\partial x}\right)+\frac{\partial}{\partial y}\left(\frac{\rho h^{3}}{\eta} \frac{\partial p}{\partial y}\right)=6\left\{u \frac{\partial \rho h}{\partial x}+v \frac{\partial \rho h}{\partial y}+2 \frac{\partial \rho h}{\partial t}\right\} \\
& h=h_{0}+s+\delta
\end{aligned}
$$

where, deflection $\delta$ at any $(x, y)$ location in the contact is obtained as the result of all pressure elements $p\left(x_{1}, y_{1}\right)$ over the contact domain in a similar manner to that described by equation (1).

Ignoring any thixotropic or bulk thermal rheological behaviour of the lubricant (i.e. pressure dependent iso-thermal conditions only):

For density [10]: $\frac{\rho}{\rho_{0}}=1+\frac{0.6 p}{1+1.7 p}$

And for viscosity [60]: $\frac{\eta}{\eta_{0}}=\left(\frac{\eta_{\infty}}{\eta_{0}}\right)^{1-\left(1+p / c_{p}\right)^{2}}$

Kushwaha et al [28] solved the above set of equations under quasi-static condition to explain the physics of side constriction, observed by Wymer and Cameron [59]. This means that $\frac{\partial h}{\partial t}=0$. Figure 11 shows their numerical predictions and the corresponding photomicrograph taken by Wymer and Cameron [59]. Once good agreement was observed between the predictions and observations, a series of simulations for various roller end-profiles revealed that sharp edges of a roller inhibits formation of a coherent film due to islands of high pressure spikes. The flow patterns revealed that the lubricant flows around such high pressure regions, in much the same manner observed by JohnsRahnejat [56] (see low pressure shoulders to the Hertzian contact in figure 10) and Wedeven [58]. 

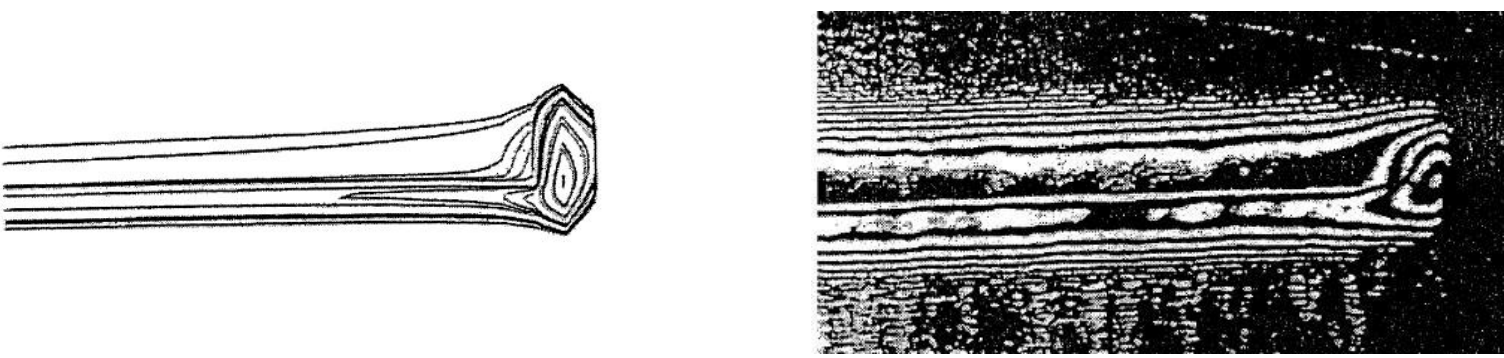

a)- Numerical prediction

b)- Interferogram

Figure 11: Comparison of predicted oil film contour with experiment (Kushwaha et al [28])

\section{6- Nano-tribology}

In nano-scale conjunctions which are progressively encountered with a growing trend in component miniaturisation or in bio-inspired investigations, other phenomena than those encountered at micro-scale become significant. To observe these differences, the same theme of a roller impacting a semi-infinite elastic half-space is used, but with much reduced roller physical attributes.

\section{1- Adhesion in contact of rough surfaces}

In practice engineering surfaces are rough. Therefore, contact between them (regardless of their topographical roughness) can be seen as the summation of a large number of individual asperity-pairs. For a first approximation the asperities may be considered to be hemispherical [61]. Figure 12 shows geometry of a group of such asperities.

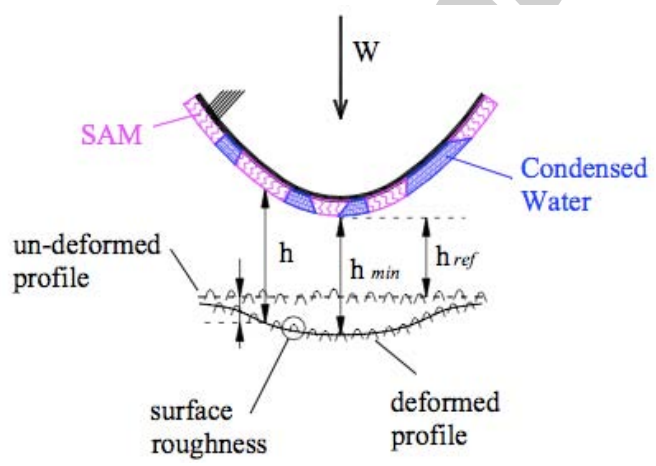

a) Roller impacting a rough surface

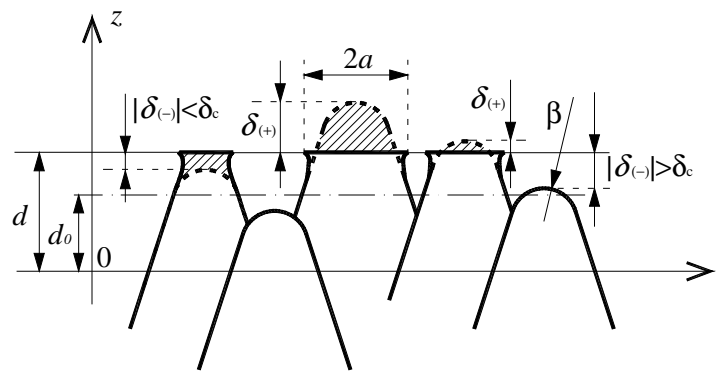

b) Surface roughness

Figure 12: Rough surface contact

At any instant of time, a number of contacting asperity-pairs may be compressed, whilst some others may be stretched due to work of adhesion. The force of adhesion between 
any pair of asperities may be approximated, for example using the model proposed by Johnson and Sridhar [62] as:

$$
P=P_{0}-P_{a}=\frac{4 E a^{3}}{3 R}-\sqrt{8 \pi a^{3} \Delta \gamma E^{\prime}}
$$

This model considers that contribution due to deformation (compression) corresponds to a Hertzian contact, whilst the adhesion component occurs according to free surface energy effect. The dimensionless load and surface deflection are expressed as [61]:

$$
\left\{\begin{array}{l}
\bar{P}=\bar{a}^{3}-\sqrt{2 \bar{a}^{3}} \\
\bar{\delta}=\bar{\delta}_{0}-\bar{\delta}_{a}=3^{2 / 3} \bar{a}^{2}\left(1-\frac{2}{3} \sqrt{2} \bar{a}^{-3 / 2}\right)
\end{array}\right.
$$

where:

$$
\begin{aligned}
& \bar{a}=a\left(4 E^{\prime} / 9 \pi \Delta \gamma \beta^{2}\right)^{1 / 3} \\
& \bar{\delta}=\delta\left(16 E^{\prime 2} / 9 \pi^{2} \Delta \gamma^{2} \beta\right)^{1 / 3} \\
& \bar{P}=P / 3 \pi \Delta \gamma R
\end{aligned}
$$

Equation (26) is solved numerically $(\bar{P}=f n(\bar{\delta}))$. It should be noted that this equation predicts the behaviour of an asperity pair. To account for the interaction of rough surfaces, Fuller and Tabor [61] proposed a normal distribution for asperity height. Therefore, the probability for an asperity to have the height between $z$ and $z+d z$ is:

$$
\phi(z)=\frac{1}{\sqrt{2 \pi}} \exp \left(-\frac{z^{2}}{2 \xi^{2}}\right)
$$

The number of participating asperities is:

$$
n=S \frac{N}{\xi \sqrt{2 \pi}} \int_{z_{1}}^{z_{2}} \exp \left(-z^{2} / 2 \xi^{2}\right) d z
$$

The force between two interacting surfaces can be computed as $[61,63]$ (see figure 12):

$$
F_{a}=\frac{n P_{c}}{\sqrt{2 \pi}} \int_{-L}^{\infty} f n\left(\frac{\Delta}{\Delta_{c}}\right) \exp \left\{-\frac{1}{2}(h+\Delta)^{2}\right\} d \Delta
$$

where:

$$
\begin{aligned}
& P_{c}=3 \pi \beta \Delta \gamma / 2 \\
& \delta_{c}=\left(9 \beta P_{c} / 4 E^{\prime}\right)^{2 / 3} / 3 \beta
\end{aligned}
$$




$$
\Delta=\delta / \sigma ; \quad \Delta_{c}=\delta_{c} / \sigma ; h=d / \sigma
$$

The above model is referred to as the JKR model [64] which is suitable for fairly compliant asperities. For stiffer asperities another model, known as the DMT [65] can be employed. As Grierson et al [66] points out there is a significant interval in asperity compliance between these alternative models, and others may be formulated. One notable model is that of Maguis-Dugdale [67].To differentiate between the two classical models it is customary to compute the Tabor parameter as: $\mu=\left(\beta^{1 / 3} \Delta \gamma^{2 / 3} /\left[E^{\prime} / 2\right]^{2 / 3} \varepsilon\right)[68,69,70]$, where $\varepsilon$ is the acting range for the surface forces and $\Delta \gamma=\gamma_{1}+\gamma_{2}+\gamma_{12}$. For the JKR approach to be used $\mu$ should be larger than 5 .

\section{2- Mensicus and hydration forces in asperity interactions}

Many micro-mechanisms are intended to operate in normal atmosphere or in some cases those in a protective atmosphere can be subject to ingression of moisture, such as MEMS gears [71]. The condensed thin layer of water can form menisci between opposing asperities on conjunctional surfaces. These menisci can add to the work of adhesion [72, 73].

Riedo et al [74] have shown that between two very proximate dry surfaces water condenses and forms a thin film (several molecular diameters thick). For micro-scale applications, this thin film can be neglected. However, this cannot be assumed at nanoscale, where the surface roughness is of the same order as that of the condensed layer of water. If two asperities mutually approach to within this thin layer of condensed water, a nano-scale meniscus bridge would form between them. Then, the attractive meniscus action would tend to bring the two asperities even closer to each other.

When the distance between the two submerged asperities becomes quite small, a repulsive hydration component can also be encountered. Hydration has an oscillatory behaviour, very similar to the solvation effect near solid boundaries $[41,72,74]$. However, this oscillatory behaviour is only noted for molecularly smooth surfaces [72] and has been traditionally studied through Monte Carlo simulations [72]. These studies have shown oscillatory variations in fluid density near solid molecularly smooth barriers which can deviate significantly from the bulk density of a fluidic medium [38,42,72,75]. Hydration follows a similar behaviour, variously suggested to be oscillatory monotonic. However in relatively rough contact conjunctions, the oscillatory behaviour of hydration is deemed insignificant, making it purely monotonic. This is in line with suggestions put forward by Israelachvili [72].

The shape of a meniscus between two asperities with equivalent radius $R_{e}$, is computed by integrating the Young-Laplace equation: $p_{o}-p_{i}+\gamma_{l v}\left(1 / r_{1}+1 / r_{2}\right)=0$, where $r_{1}$ and $r_{2}$ are the two radii of the meniscus $[72,73]$. The resultant meniscus force for a bridge is:

$$
f_{m}=-2 \pi R \gamma_{l v}\left(\cos \theta_{1}+\cos \theta_{2}\right)
$$


where: $\theta_{1}$ and $\theta_{2}$ are the contact angles that a film of water makes with the two contacting surfaces.

The meniscus force tends to stick the contiguous surfaces together. This is detrimental for MEMS gears, particularly when operating at low speeds. Thus, it is commonplace to cover the teeth surfaces by hydrophobic mono-layers, which self-assemble when applied, referred to as self-assembled mono-layers (SAM). The contact angles made by water with these mono-layers are large, indicating strong hydrophobicity, whilst for unprotected silica surfaces (the material of choice for MEMS devices due to good thermal stability) the contact angles are quite small (strongly hydrophilic). Therefore, the SAM inhibits the formation of menisci, whilst the rough silica surfaces encourage it.

At very small separation between submerged surfaces, a repulsive potential is noted. This potential can be considered to be an exponential decay of the form $[72,75]$ :

$$
w_{H}=2 \gamma_{l v} e^{-(D-z) / \lambda_{0}}
$$

where:

$$
\begin{aligned}
& \gamma_{l v} \in[10 \div 50] \mathrm{mJ} / \mathrm{m}^{2} \\
& \lambda_{0} \approx 1.5 \mathrm{~nm}(\sim 6 \text { times the molecule of water })
\end{aligned}
$$

The hydration pressure between a pair of submerged asperities is given as:

$$
P_{H}=\frac{\partial w_{H}}{\partial(D-z)}=2 \frac{\gamma_{l v}}{\lambda_{0}} e^{-(D-z) / \lambda_{0}}
$$

The hydration force between two asperities acts through their enveloping small micromeniscus. Therefore, to quantify this force, the size of the meniscus should be computed. The equilibrium meniscus curvature radius is obtained considering the relative vapour pressure $\left(p / p_{s}\right)$ as [72]:

$$
1 /\left(1 / r_{1}+1 / r_{2}\right)=\gamma_{l y} V / R T \log \left(p / p_{s}\right)
$$

where it is acceptable to assume that for a spherical concave water meniscus $r_{1}=r_{2}=r$ [72].

Teodorescu and Rahnejat [76] have shown that for a surface $S$, considered to have a normally distributed asperity height the meniscus and the hydration forces are:

$$
F_{h}=S N \sqrt{\frac{2}{\pi}} \frac{\gamma_{l v}}{\lambda_{0} \xi} \int_{D-h_{m}}^{D} e^{-\frac{z^{2}}{2 \xi^{2}}} e^{-\frac{D-z}{\lambda_{0}}} d z
$$

and: 


$$
F_{m}=-S N R \gamma_{l v} \frac{\sqrt{2 \pi}}{\xi}\left(\cos \theta_{1}+\cos \theta_{2}\right) \int_{D-h_{m}}^{D} e^{-\frac{z^{2}}{2 \xi^{2}}} d z
$$

Now, equations (34), (35) and (29) give the total contact load as:

$W=\iint\left(F_{a}+F_{m}+F_{h}\right) d x d y$

It is generally noted that one may broadly distinguish between the micro-scale and nanoscale tribo-dynamics phenomena by the apparent loss of a continuum. Meniscus action and hydration as physical phenomena exist at both scales, but only become significant at molecular level interactions. Therefore, a definitive boundary cannot be assumed, except for the fact that most molecular behaviour are functions of the ratio of the size of a body to that of the system (molecule of the intervening fluid to the gap size) [72]. In the case of meniscus action the height of a bridge is dependent on the layer of condensation which can be computed according to saturation pressure and condensation activation time [74].

Finally, the equation of motion is obtained as:

$m \ddot{h}_{r e f}=W-m g$

The solution of this equation in suitably small time steps provides the gap $h_{\text {ref }}$.

Clearly, classical Hertzian theory deals with the totally elastic impact of a roller on a semi-infinite elastic half-space, where the kinetic energy converts to stored strain energy upon impact without any losses. This stored kinetic energy is then gradually converted back into kinetic energy upon rebound. Therefore, the centre of the roller describes a path determined by the impact force, given by the Hertzian load-deflection relationship $F=k \delta^{3 / 2}$. For impact of a unprotected roller (without SAM) on a rough surface (also unprotected), the impact kinetic energy must overcome the work of adhesion and break any formed micro-menisci, whilst aided at vanishing separations by the hydration potential. The net stored energy for rebound is therefore less than the impact kinetic energy. Thus, the load-displacement characteristics differ in impact and rebound as shown in figure 13 (a) for the first rebound. Note that the area bounded by the impactrebound loop represents the loss of energy. Such characteristics may be considered as hysteretic behaviour. Figure 13 (b) shows a series of rebounds until the roller comes to rest. When a SAM covered surface is employed, the effect of hydration is enhanced, whilst that of adhesion and meniscus action are significantly reduced. Thus, the impact and rebound paths almost coincide (i.e. no significant loss of energy occurs, thus many bounces can occur), although the characteristics differ from Hertzian theory because of the prevailing kinetics (see figure 14). This explains the effectiveness of the SAM protected MEMS gears (particularly at lower speeds), but use of Hertzian theory is not permissible. The roller and the height from which it is released is chosen to represent typical impact conditions experienced in MEMS gears. 
Returning to the case of unprotected surfaces, figure 15 shows that the loss of energy due to the work of adhesion reduces the rebound velocity, until an insufficient impact energy exists to overcome the combined effect of meniscus attraction of asperity pairs and their adhesion. In effect there is a limiting velocity needed for the roller to bounce, which may be considered as the escape velocity for any combination of rough impacting wet solids.

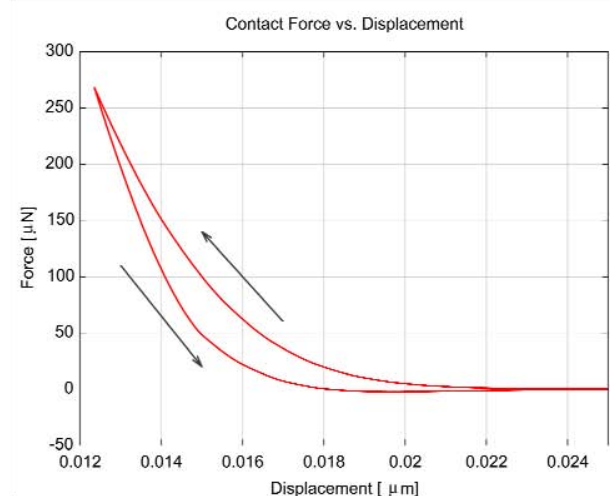

a)

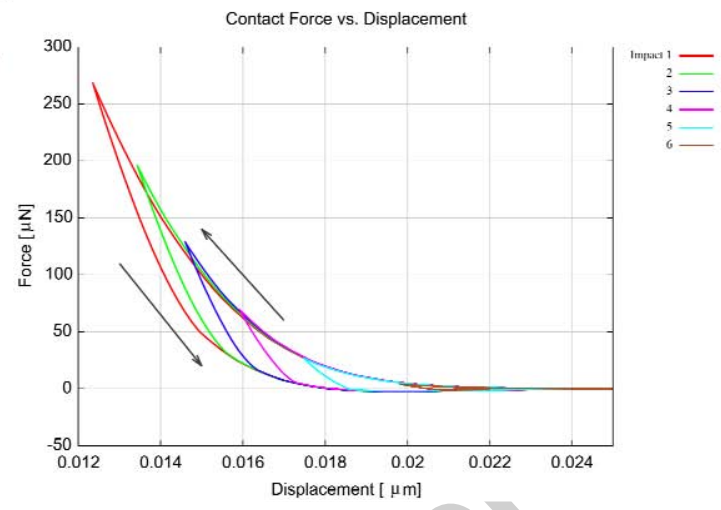

b)

Figure 13: Impact and rebound in a nano-scale conjunction

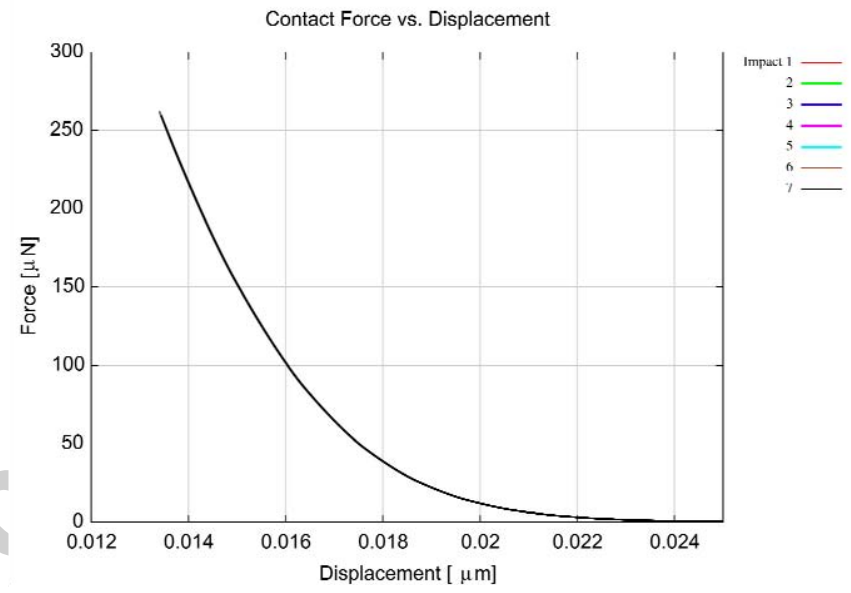

Figure 14: Impact-rebound characteristics in nano-scale for a hydrophobic surface 


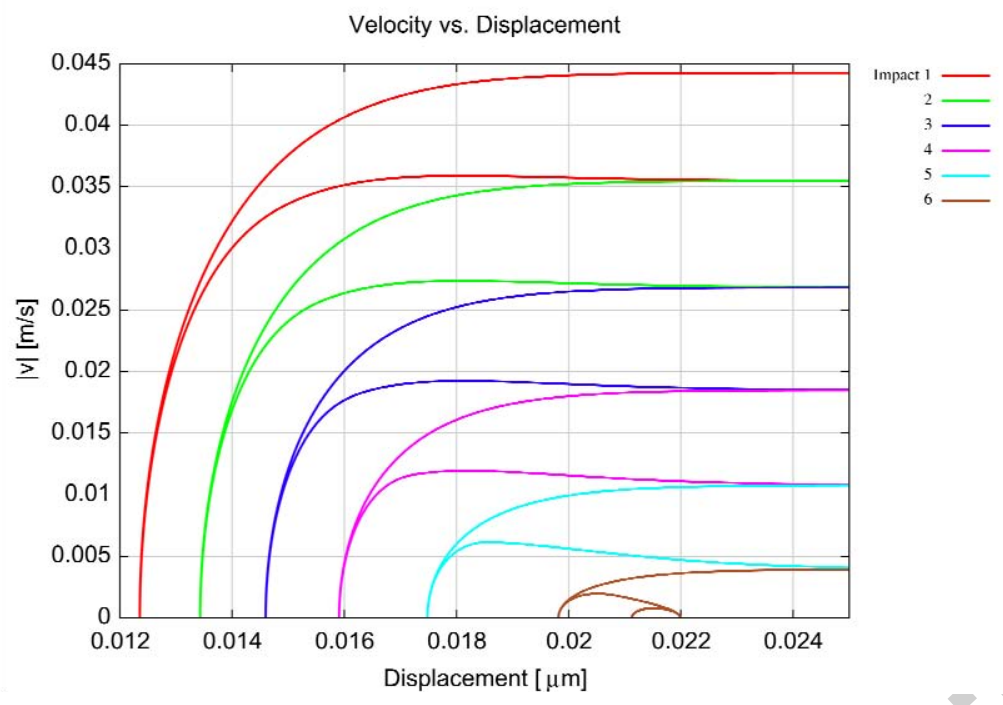

Figure 15: Impact and rebound velocities for multiple bounces

It is clear that unlike micro-scale conjunctions nano-scale asperity interaction is affected by asperity pair adhesion as well as by effect of micro-scale menisci between them, under normal atmosphere. Other effects such as van der Waal's interaction and hydration at very close range also play a role.

\section{7- Concluding Remarks}

This paper provides a brief review of some of the tribo-dynamics phenomena. It shows how evolving knowledge has paved the way for the understanding and in some cases design of machines and mechanisms with progressively thinner lubricant film conjunctions. In Reynolds' time, film thicknesses of the order of tens of micrometer existed in rather crude bearings. The steadily falling oil film thickness and better design of bearings reported by Dowson [1] have been as a result of the evolving understanding of elastohydrodynamic phenomenon. Thus, as Dowson [77] has pointed out "talk of submicrometer films in a number of situations .... has become commonplace". With lightly loaded contacts ultra-thin films have been noted [39,40]. It has also become clear that the mechanisms giving rise to formation of these thin films are dependent upon physical chemistry of intervening fluids and surface energy effects, rather than the usual piezoviscous action. The whole new area of nano-tribology is now open to further fundamental research, with emerging and growing applications in MEMS devices. Furthermore, a new area of bio-inspired nano-tribology is fast emerging [78-80], in which some of the force laws described in this paper play significant roles. Elastohydrodynamics is still a developing area of research, where thin films formed on thin bonded layers, such as coatings need careful investigation. In nano-conjunctions fundamental studies of competing force laws are still in their infancy.

\section{8- References:}

[1] Dowson, D. History of Tribology, Longman, London, 1979 
[2] L. M. H. Navier, "Memoire sur les lois du mouvement des fluides", Memoires de l'Academie Royale des Sciences, 6, 1827

[3] G. G. Stokes, "On the Theories of the Internal Friction of Fluids in Motion, and of the Equilibrium and Motion of Elastic Solids", Trans. Camb. Phil. Soc., 9, 1851.

[4] Tower, B, "First report on friction experiments", Proc. Inst. Mech. Engrs. Nov. 1883, pp.632-66, 2nd Report ibid,1885 pp.58-70, 3rd Report, ibid , 1888, pp.173205, 4th Report, ibid, 1891, pp. 111-140.

[5] O. Reynolds, "On the theory of lubrication and its application to Mr Beauchamp Tower's experiments, including an experimental determination of the viscosity of olive oil', Phil. Trans. Roy. Soc., 177, 1886, pp.157-234.

[6] A. N. Grubin, "Investigation of Scientific and Industrial Research" Central Scientific Research Institute for Technology and Mechanical Engineering, Moscow(Book 30), 1949.

[7] H. Hertz, "On the contact of elastic solids", J. Reine Angew. Math., 1881.

[8] A. I. Petrusevitch, "Fundamental Conclusions from the Contact-Hydrodynamic Theory of Lubrication", Izvestia Uzbekist. Fil. Akad. Nauk. S.S.S.R. (OTN), 2, 1951.

[9] D. Dowson, and G. R. Higginson, Elasto-Hydrodynamic Lubrication, Pergamon Press Ltd., 1966.

[10] D. Dowson and G. R. Higginson, "A Numerical Solution to the elastohydrodynamic Problem", J. Mech. Engng. Sci., 1, 1959.

[11] J. F. Archard, F. C. Gair and W. Hurst, "The Elastohydrodynamic Lubrication of Rollers", Proc. Roy. Soc., A262, 1961.

[12] R. R. Stephenson and J. F. Osterle, "A Direct Solution of the Elastohydrodynamic Lubrication Problem", Trans. ASLE, 5. 1962

[13] B. Sternlicht, P. Lewis and P. Flynn, "Theory of Lubrication and Failure of Rolling Contacts" Trans. ASME. J. Basic Engng., 83 (D), 1961.

[14] A. W. Crook, "The Lubrication of Rollers III., A Theoretical Discussion of Friction and the Temperature in the Oil Film", Phil. Trans. Roy. Soc., A254, 1961.

[15] A. Cameron and R. Gohar, "Theoretical and Experimental Studies of the Oil Film in Lubricated Point Contacts", Proc. Roy. Soc., A291, 1966

[16] J. F. Archard and E. W. Cowking, "Elastohydrodynamic Lubrication at Point Contacts", Proc. Inst. Mech Engrs., 180 (3B), 1965.

[17] A. P. Ranger, C. M. M. Ettles and A. Cameron, "The Solution of Point Contact EHL Problem", Proc. Roy. Soc., A346, 1975.

[18] D. Dowson and P. D. Swales, "An Elastohydrodynamic Approach to the Problem of Reciprocating Seals”, Paper F3, Third Int. Conf. Fluid Sealing, 1967.

[19] C. J. Hooke and J. P. O. O'Donoghue, "Elastohydrodynamic Lubrication of Soft, Highly Deformed Contacts", J. Mech. Eng. Sci., 14, 1972.

[20] K. P. Baglin and J. F. Archard, "An Analytic Solution of the Elastohydrodynamic Lubrication of Materials of Low Elastic Modulus", Proc. Inst. Mech. Engrs. C3, 1972.

[21] H. Christiansen, "Elastohydrodynamic Theory of Spherical Bodies in Normal Approach", Trans. ASME, J. Lubn. Tech., 92, 1970.

[22] D. Dowson, B. L. Ruddy and P. N. Economou, "The Elastohydrodynamic Lubrication of Piston Rings”, Proc. Roy. Soc., A386, 1982. 
[23] M-T Ma, I. Sherrington and E. H. Smith, "Analysis of Lubrication and Friction for a Complete Piston-Ring Pack with an Improved Oil Availability Model: Part 1: Circumferentially Uniform Film“, Proc. Instn. Mech. Engrs., 211, 1997, pp. 1-15.

[24] A. A. Lubrecht and C. H. Venner, "EHL Lubrication of Rough Surfaces" Proc. Instn. Mech. Engrs., 213, 1999, pp. 397-404.

[25] D. Jalali-Vahid, H. Rahnejat, R. Gohar and Z. M. Jin, "Comparison between Experiments and Numerical Solutions for Isothermal Elastohydrodynamic Point Contacts" J. Phys. D: Appl. Phys. 31, 1998, pp. 2725-32

[26] D. Jalali-Vahid, H. Rahnejat, Z.M. Jin and D. Dowson, “Transient Analysis of Isothermal Elastohydrodynamic Circular Point Contacts" Proc. Instn. Mech. Engrs., Part C: J. Mech. Engrs. 215, 2001, pp.1159-73.

[27] M. Kushwaha and H. Rahnejat, "Transient Elastohydrodynamic Lubrication of Finite Line Conjunction of Cam to Follower Concentrated Contact", J. Phys., Part D: Appl. Phys., 35, 2002, pp.2872-2890.

[28] M. Kushwaha, H. Rahnejat and R. Gohar, "Aligned and Misaligned Contacts of Rollers to Races in Elastohydrodynami Finite Line Conjunctions" Proc. Instn. Mech. Engrs. part C: J. Mech. Eng. Sci. 216, 2002, pp.1051-70.

[29] Mei X and Xie Y, "Numerical Solution of Impact Vibration in a Valve Train", Trans. CSICE, 11(3), 1993, pp. 249-254.

[30] S. Balakrishnan and H. Rahnejat, "Isothermal Transient Analysis of Piston Skirt-toCylinder Wall Contacts under Combined Axial, Lateral and Tilting Motion", J. of Phys., D: Appl. Phys., 38, 2005, pp.787-799

[31] M. Kushwaha and H. Rahnejat, "Transient Concentrated Finite Line Roller-to-Race Contact under Combined Entraining, Tilting and Squeeze Film Motions “, J. Phys. D: Appl. Phys. 37, 2004, pp. 2018-2034

[32] D. Dowson and D. Jones, "Lubricant Entrapment between Approaching Elastic Solids" Nature, 214, 1967, pp. 947-8

[33] M. M. A. Safa and R. Gohar, "Pressure Distribution under a Ball Impacting a Thin Lubricant Layer", Trans. ASME. J. Trib., 108, 1986.

[34] M. F. Al-Samieh and H. Rahnejat, "Physics of Lubricated Impact of a Sphere on a Plate in a Narrow Continuum to Gaps of Molecular Dimension”, J. Phys. D: Appl. Phys., 2002, pp. 2311-26.

[35] Z. M. Jin and D. Dowson, "Elastohydrodynamic Lubrication in Biological Systems”, Proc. Instn Mech. Engrs., 219 (5), 2005, pp. 367-380.

[36] D. Dowson, Biotribology, Professional Engineering Publishing, London, 2005.

[37] A.Kobayashi, I. Yamamoto and T. Aoyama, "Tribology of a Snail (Terrestrial Gastropod)", Proc. 29th Leeds-Lyon Symp. on Trib., Tribological research and Design for Engineering Systems, Elsevier B.V., 41, 2004, pp. 429 - 436.

[38] D. Y. C. Chan and R. G. Horn "The Drainage of the Thin Liquid Films Between Solid Surfaces" J. Chem. Phys., 83, 1984, pp.5311-24.

[39] H. Matsuoka and T. Kato, "An Ultra-Thin Liquid Film Lubrication TheoryCalculation Method of Solvation Pressure and its Applications to EHL Problem" Trans. ASME, J. Trib., 119, 1997, pp. 217-26.

[40] M. F. Al-Samieh and H. Rahnejat, "Nano-Lubricant Film Formation due to Combined Elastohydrodynamic and Surface Force Action under Isothermal Conditions", Proc. Instn. Mech. Engrs., 215, 2001. 
[41] M. F. Al-Samieh and H. Rahnejat, "Ultra-Thin Lubricating Films under Transient Conditions” J. Phys. D: Appl. Phys., 34, 2001, pp. 2610-21.

[42] M.F. Al-Samieh, H. Rahnejat and D. Dowson, "Molecular-Lelel Tribology Under Transient Conditions", $7^{\text {th }}$ Biennial ASME Conference on Engineering Systems Design and Analysis (ESDA), Manchester, UK, July 19-22, 2004.

[43] P. M. Johns and R. Gohar, "Roller Bearing under Radial and Eccentric loads", Trib. Int., 13, 1981, pp. 131-136.

[44] A. Mostofi and R. Gohar, "Elastohydrodynamic Lubrication of Finite Line Contacts", Trans. ASME, J. Lubn. Tech., 105, 1983, pp.598-604

[45] M. Koshy and R. Gohar, "Pressure distribution on radially loaded rollers", Proc. 18th Int. Mach. Tool Design \& Res. Conf., II, 1977, pp.595-604.

[46] P. M. Johns, The design of cylindrical rollers for use in shaft and bearing systems, MSc Dissertation, Imperial College of Science and Technology, University of London, 1978, London, UK.

[47] V. Votsios, Contact Mechanics and Impact Dynamics of Non-Conforming Elastic and Viscoelastic Semi-infinite or Thin Bonded Layered Solids, PhD thesis, Loughborough University. 2003, Loughborough, UK

[48] K.L. Johnson, Contact Mechanics, Cambridge University Press, 1985, Cambridge, UK.

[49] G. R. Naghieh, H. Rahnejat and Z.M. Jin, "Characteristics of Frictionless Contact of Bonded Elastic and Viscoelastic Layered Solids", Wear, 232, 1998, pp. 243-249.

[50] M. Teodorescu and H. Rahnejat, "Mathematical Modelling of Layered Contact Mechanics of Cam-Tappet Conjunction”, Appl. Math. Model., 31, 2007, pp. 26102627.

[51] I. N. Sneddon, Fourier Transforms, McGraw-Hill Book Company, Inc., 1951, New York.

[52] T. C. O’Sullivan, and R.B. King, "Sliding Contact Stress Field due to a Spherical Indenter on a Layered Elastic Half-space”, Trans. ASME, J. Trib, 110, 1988, pp.235-240.

[53] S. Tolanski, An introduction to Interferometry, $4^{\text {th }}$ edition, Longmans, 1966, London, UK.

[54] R. Gohar, Elastohydrodynamics, Imperial College Press, 2001, London, UK.

[55] P.M. Johns-Rahnejat and R. Gohar, "Measuring Contact Pressure Distributions under Elastohydrodynamic Point Contacts" Tribotest, 1, 1994, pp. 33-53.

[56] P.M. Johns-Rahnejat, Pressure and Stress Distribution under Elastohydrodynamic Point Contacts, PhD Thesis, Imperial College of Science and Technology, University of London, 1988, London, UK.

[57] N. Tipei, "Boundary Conditions of a Viscous Flow Between Surfaces with Rolling and Sliding Motion", Trans. ASME., J. Lubn. Tech., 1968.

[58] L. D. Wedeven, Optical Measurements in Elastohydrodynamic Rolling Contact Bearings, PhD Thesis, Imperial College of Science \& Technology, University of London, 1970, London, UK.

[59] D. G. Wymer and A. Cameron, "Elastohydrodynamic Lubrication of a Line Contact”, Proc. Instn Mech. Engrs, 188, 1974, pp. 221-238.

[60] A. Reolands, Correlation aspects of visco-temperature-pressure relationships of lubricating oils, PhD thesis, Delft University of Technology, 1966, The 
Netherlands.

[61] K. N. G. Fuller and D. Tabor, "The Effect of Surface Roughness on the Adhesion of Elastic Solids” Proc. Roy. Soc., A345, 1975, pp. 327-342.

[62] K.L. Johnson and I. Sridhar, "Adhesion Between a Spherical Indenter and an Elastic Solid with a Compliant Elastic Coating”, J. Phys. D: Appl. Phys. 34, 2001, pp. 683-689.

[63] M. Teodorescu and H. Rahnejat, "Dry and Wet Nano-Scale Impact Dynamics of Rough Surfaces with or without a Self-Assembled Mono-Layer", Proc. Instn. Mech. Engrs. , J. Nanoengng. and Nanosys., doi: 10.1243/174034 99JNN101

[64] K. L Johnson., K. Kendall and A.D. Roberts, "Surface energy and the contact of elastic solids” Proc. Roy. Soc., Series A, 324 (1558) 1971, pp. 301-313.

[65] K. L.Derjaguin, V. M.Muller and Y. P. Toporov, "Effect of contact deformation on the adhesion of particles” J. Colloid Interface Sci. 53, 314 (1971). pp.314-26

[66] Grierson D. S., Flater E. E. and Carpick R. W., "Accounting for the JKR-DMT transition in adhesion and friction measurements with atomic force microscopy", $\mathrm{J}$. Adhesion Sci. Technol., Vol. 19, No. 3-5, pp. 291 - 311 (2005)

[67] D. Maguis, 1992, “Adhesion of Spheres: The JKR-DMT Transition Using a Dugdale Model,'’ J. Colloid Interface Sci., 150, pp. 243-269.

[68] D. Tabor (1977) "Surface forces and surface interactions" J. Colloids Interface Sci. $58,1,2-13$.

[69] K. L. Johnson and J A Greenwood 1997 "An adhesion map for the contact of elastic spheres" J. Colloids Interface Sci. 192 326-33

[70] K.L. Johnson, "Adhesion and friction between a smooth elastic spherical asperity and a plane surface", Proc. R. Soc. Lond. A (1997) 453, 163-179

[71] Tanner D. M., Smith N. F., Irwin L. W., Eaton W. P., Helgesen K. S., Clement J. J., Miller W. M., Walraven J. A., Peterson K. A., Tangyunyong P., Dugger M. T., Miller S. L., (2000) "MEMS Reliability: Infrastructure, Test Structures, Experiments, and Failure Modes", SANDIA REPORT, SAND2000-0091

[72] J. N. Israelachvili, Intermolecular and Surface Forces. Academic Press, New York, USA, 1992.

[73] Bhushan, B, Handbook of Micro/Nanotechnology, $2^{\text {nd }}$ edition, CRC Press, Boca Raton, Florida, 1999.

[74] E. Riedo, F. Lévy and H. Brune, "Kinetics of Capillary Condensation in Nanoscopic Sliding Friction”, Phys. Rev. Lett. 88. (18), 2002.

[75] M. Teodorescu, S. Balakrishnan and H. Rahnejat, "Physics of Ultra-Thin Surface Films on Molecularly Smooth Surfaces”, Proc. Instn. Mech. Engrs., J. NanoEngng. and Nanotech., 220 (1), 2006, pp. 7-19.

[76] M. Teodorescu and H. Rahnejat, "Newtonian Mechanics in Scale of Minutia", Proc. Instn. Mech. Engrs., J. Multi-Body Dyn., 222, 2008.

[77] D. Dowson, “Developments in lubrication-the thinning film”, J. Phys. D: Appl. Phys., 25, 1992, pp.334-339.

[78] M. Scherge and S.N. Gorb, From micro to nano-tribology- Nature's Solutions, Springer-Verlag, Berlin, Heildelberg, 2001.

[79]- B. Schubert, J. Lee, C. Majidi and R.S. Fearing, "Sliding-induced adhesion of stiff polymer microfiber arrays. II. Microscale behaviour" Journal of the Royal Society, online, 2008, doi: 10.1098/rsif.2007.1309. 
[80]- M. Teodorescu and H. Rahnejat, "Nano-Scale contact model for Microfiber Tip attachment, detachment and Friction”, Proc. STLE/ASME Int. Joint Trib. Conf., IJTC2008, October 20-22, 2008, Miami, Florida, USA 